Estudios de la Paz y el Conflicto

Revista Latinoamericana

IUDPAS-UNAH

Volumen 1, Número 1, pp. 74-96

ISSN-e: 2707-8922 / ISSN: 2707-8914

DOI: $10.5377 /$ rlpc.v1i1.9517

Enero-junio 2020

\title{
PAZ E CRIME ORGANIZADO NA AGENDA 2030: O PAPEL DA ORGANIZAÇÃO DOS ESTADOS AMERICANOS
}

\author{
PEACE AND ORGANIZED CRIME ON THE 2030 AGENDA: THE ROLE OF THE \\ ORGANIZATION OF AMERICAN STATES
}

\author{
Marcos Alan S. V. Ferreira \\ Universidade Federal da Paraíba \\ marcosalan@gmail.com \\ Anna Beatriz Ramalho Gonçalves \\ Universidade Federal da Paraíba \\ biaramalho2109@gmail.com \\ Mirelle Lages Lucena \\ Universidade Federal da Paraíba \\ mirellelucena@gmail.com
}

Cómo citar / citation

Ferreira, M., Ramalho, A., Lages M. (2020). "Paz e crime organizado na agenda 2030: o papel da Organização dos Estados Americanos", Estudios de la Paz y el Conflicto, Revista Latinoamericana, Volumen 1, Número 1, 74-96. DOI: 10.5377/rlpc.v1i1.9517

\begin{abstract}
Resumo
Este artigo, fundamentado nas discussões sobre paz e desenvolvimento promovidos na Agenda 2030, busca refletir como o ODS 16.4 pode contribuir nos estudos para a paz ao reconhecer a importância da cooperação no combate ao crime organizado. Há no mainstream dos estudos de paz uma tendência a perceber a violência somente em contextos de conflitos armados regulares, na qual o Estado é a principal unidade de análise. Neste sentido, exploramos a seguinte pergunta: quais os caminhos da cooperação internacional promovidos pela Agenda 2030, em seu objetivo 16.4, podem avançar com a atuação da Organização dos Estados Americanos? Metodologicamente fazemos uma análise documental desde 2015, combinados com análise exploratória com enfoque nos estudos críticos de paz, bem como a observação do contexto atual da segurança pública na região latino-americana. Espera-se demonstrar a relevância de examinar o crime organizado como um impedimento à construção de sociedades pacíficas regionalmente.
\end{abstract}




\title{
Palavras-chave
}

Paz; crime organizado; objetivos do desenvolvimento sustentável.

\begin{abstract}
This article, based on the discussions on peace and development promoted in the 2030 Agenda, seeks to reflect how SDG 16.4 can contribute to peace studies by recognizing the importance of cooperation in combating organized crime. There is a tendency in mainstream peace studies to perceive violence only in contexts of regular armed conflict, in which the state is the main unit of analysis. In this sense, we explore the following question: what are the paths of international cooperation promoted by the 2030 Agenda, in its objective 16.4, that can advance the actions of the Organization of American States? Methodologically, we have been carrying out a documentary analysis since 2015, combined with an exploratory analysis focusing on critical peace studies, as well as the observation of the current context of public security in the Latin American region. It is hoped to demonstrate the relevance of examining organized crime as an impediment to building regionally peaceful societies.
\end{abstract}

\section{Keywords}

Peace; organized crime; sustainable development goals.

\section{Resumen}

Este artículo, basado en las discusiones sobre paz y desarrollo promovidas en la Agenda 2030, busca reflejar cómo el ODS 16.4 puede contribuir a los estudios de paz al reconocer la importancia de la cooperación en la lucha contra el crimen organizado. Hay una tendencia en la corriente principal de los estudios de paz a percibir la violencia solo en el contexto de un conflicto armado regular, en el que el estado es la principal unidad de análisis. En este sentido, exploramos la siguiente pregunta: ¿qué caminos de cooperación internacional promovidos por la Agenda 2030, en su objetivo 16.4, pueden avanzar con la acción de la Organización de los Estados Americanos? Metodológicamente, llevamos a cabo un análisis de documentos desde 2015, combinado con un análisis exploratorio centrado en estudios críticos de paz, así como observando el contexto actual de seguridad pública en la región de América Latina. Se espera demostrar la relevancia de examinar el crimen organizado como un impedimento para la construcción de sociedades regionalmente pacíficas.

\section{Palabras clave}

Paz; crimen organizado; objetivos de desarrollo sostenible.

\section{INTRODUÇÃO}

Fundamentado teoricamente nas discussões sobre paz e desenvolvimento promovidos na Agenda 2030, o presente artigo busca refletir como o ODS 16.4 pode representar avanços nos debates dos estudos para a paz ao reconhecer a importância da cooperação no combate ao crime organizado. Em particular, ao conectar um elemento disseminador da violência que é o crime organizado com os debates sobre desenvolvimento, compreende-se aqui que o ODS

Estudios de la Paz y el Conflicto, Revista Latinoamericana, IUDPAS-UNAH, Volumen 1, Número 1, enero-junio 2020, pp. 74-96. DOI: $10.5377 /$ rlpc.v1i1.9517 
16.4 nos ajuda a retomar a criticidade inicial dos Estudos de Paz. Este campo, em seu surgimento, propusera justamente a compreensão de como o desenvolvimento socioeconômico está ligado à violência direta, sendo fundamental o entendimento de ambos (Galtung, 1969).

Tal problemática é de especial importância para a América Latina. Diante de um cenário marcado por uma rede de violência direta que é promovida pela atuação de grupos criminosos nas periferias e nos grandes centros, altas taxas de homicídios vêm sendo observadas na região, como apresentaremos em uma das seções deste artigo. Neste contexto, exploramos a seguinte pergunta: quais os caminhos de avanço da cooperação internacional promovidos pela Agenda 2030, em seu objetivo 16.4, podem ser verificados a partir da atuação da Organização dos Estados Americanos (OEA)?

Para responder a essa reflexão, conduzimos uma pesquisa exploratória fundamentada na análise dos documentos oficiais que preconizam a cooperação no organismo regional supracitado desde o ano de 2015. Foram avaliados os documentos oficiais da OEA que avançam na cooperação em temas relacionados com o ODS 16.4, assim como a literatura especializada sobre cooperação contra o crime no continente Americano. Adicionalmente, foram utilizados levantamentos bibliográficos exploratórios com enfoque nos estudos críticos de paz, bem como a observação de dados sobre o contexto atual da segurança pública na região latino-americana. Esperou-se assim demonstrar, a partir da análise da atuação da OEA, a relevância de se evidenciar o crime organizado como um impedimento à construção de sociedades pacíficas em uma agenda ampla, tal qual a dos Objetivos do Desenvolvimento Sustentável e especificamente seu objetivo 16.4.

O artigo está dividido em seis partes. Após esta introdução, apresentamos o referencial teórico conceitual utilizado, a saber, os Estudos Críticos de Paz. Em seguida, apresentamos o estado-da-arte sobre os Objetivos do Desenvolvimento Sustentável, em especial o objetivo 16.4, a saber, "até 2030, reduzir significativamente os fluxos financeiros e de armas ilegais, reforçar a recuperação e devolução de recursos roubados e combater todas as formas de crime organizado" (ONU, 2015). Logo depois, discutimos o fenômeno da violência e criminalidade na América Latina e seus impactos no desenvolvimento da região. Finalmente, na seção final que antecedem as considerações finais, discutimos os caminhos abertos para a cooperação dentro do ODS 16.4 e alguns de seus desafios, tendo como foco o caso da Organização dos Estados Americanos.

\section{ESTUDOS DE PAZ E O DEBATE SOBRE DESENVOLVIMENTO}

O fim da Segunda Guerra Mundial marcou o surgimento dos Estudos de Paz (EP) como disciplina acadêmica independente e institucionalizada, num contexto em que os traumas do então recém-encerrado conflito incentivavam a realização de estudos rigorosos que construíssem caminhos para a paz. Dessa forma, baseando-se em reflexões críticas sobre a realidade da época, o objetivo inicial da nova disciplina seria a valorização da paz sobre a guerra, por meio da elaboração de políticas relevantes sustentadas em valores éticos e morais que superassem a hegemonia do paradigma realista na explicação da guerra e da paz (Jutila, Pehkonen, y Vayrynen, 2008).

Os anos seguintes foram, então, marcados por uma fase de frenético crescimento dos EP - com o surgimento de diversos centros de pesquisa da disciplina - bem como por uma ampla aceitação das bases institucionais que guiariam seus estudos (Jutila, et al, 2008; Wiberg,

Estudios de la Paz y el Conflicto, Revista Latinoamericana, IUDPAS-UNAH, Volumen 1, Número 1, enero-junio 2020, pp. 74-96. DOI: 10.5377/rlpc.v1i1.9517 
2005). Ao mesmo tempo, emergiram as primeiras tensões conceituais e epistemológicas do campo. Essas tensões envolviam principalmente a falta de criticidade que inicialmente chamou a atenção, tornando o campo uma ciência cada vez mais burocrática focada em problem-solving (Ferreira, 2017).

Nesse contexto, o que se viu ao longo dos anos foi a perda de vitalidade da disciplina, já que seus estudiosos e seus principais periódicos permaneceram a publicar trabalhos com visões limitadas se comparadas à amplitude de implicações e aplicabilidades que os Estudos de Paz apresentam. Como afirma Jutila et al, “[...] o espírito inicial crítico e criativo da disciplina deixou de existir, restando apenas uma 'ciência normal' que não reflete suas categorias básicas ou seu papel na sociedade” (2008: 623, tradução nossa). Por conta dessa problemática, tais autores advogaram pela criação de uma comunidade epistêmica - Os Estudos Críticos para a Paz - que, baseada nas premissas das teorias sociais críticas, pudesse acolher diversas abordagens e ampliasse as questões discutidas pela disciplina.

$\mathrm{Na}$ tentativa de alargar os horizontes da disciplina, Ferreira (2017) utilizou dos Estudos Críticos para Paz em seu trabalho para demonstrar as deficiências que os Estudos de Paz tradicionais apresentam ao lidarem com importantes problemas contemporâneos. De acordo com o autor, a vertente convencional dos Estudos de Paz se fragmentou e tornou-se insuficiente, pois negligenciou as diversas abordagens das causas da violência como seu objeto de pesquisa, concentrando-se, assim, em uma visão predominantemente estatocêntrica.

Ferreira (2017) reforça em seu estudo que a natureza dos conflitos armados passou por significativa mudança nos últimos tempos e a atuação de atores não-estatais, especialmente grupos terroristas e o crime organizado, adquiriram grande relevância. Dessa maneira, tais grupos são hoje os grandes responsáveis pela propagação da violência e são considerados as principais ameaças à paz em regiões como a América Latina. Vale ressaltar ainda que essas organizações criminosas ultrapassaram os limites estatais, pois atuam estrategicamente em diversos territórios, alcançando, portanto, dimensões transnacionais (Ferreira, 2019). Devido a essa condição, o autor critica o foco dos Estudos de Paz convencionais em conflitos armados regulares, pois tal abordagem se mostra ultrapassada ao classificar como territórios pacíficos regiões em que não há grupos beligerantes de caráter político, como no caso latinoamericano. Entretanto, sabe-se que essas mesmas localizações apresentam os mais altos índices de homicídio e sofrem com o aumento exponencial da criminalidade ano após ano. Faz-se necessário também um retorno às premissas originais da disciplina de Estudos de Paz para que se analise a violência em todas suas formas e de maneira ampla. Nesse sentido, importantes conceitos devem ser relidos de maneira crítica a fim de melhor compreender novos fenômenos do Sul Global (Pureza e Cravo, 2005), como é o caso do crime organizado (Ferreira, 2017). Esta perspectiva é referendada em análises recentes, como a desenvolvida por MacGinty (2019: 5) ao afirmar que "the most urgent problem by far facing peace and conflict studies is the division between those working in the Global South and those in the Global North and the need for meaningful interaction and partnership".

Em vista disso, é mister retomar elementos constitutivos da criticidade da área proposta inicialmente por Johan Galtung ao conectar desenvolvimento social e superação das violências existentes. Galtung (1969) aborda a necessidade de construção de um marco teórico para o próprio conceito de paz. Desse modo, ele elabora a definição da paz como sendo a ausência da violência. Para tanto, Galtung (1969) inicialmente constrói um aparato conceitual sobre o que seria essa violência. Preliminarmente, admite-se a existência de duas formas de violência: violência direta e violência estrutural. A primeira faz referência à

Estudios de la Paz y el Conflicto, Revista Latinoamericana, IUDPAS-UNAH, Volumen 1, Número 1, enero-junio 2020, pp. 74-96. DOI: 10.5377/rlpc.v1i1.9517 
violência física executada diretamente que causa morte ou dano físico/ferimento. Já a segunda se refere à desigualdade de poder e de condições de vida, uma realidade na qual os recursos da sociedade são distribuídos assimetricamente. Em resumo, esta última pode ser definida como uma consequência das desigualdades. Posteriormente, Galtung amplia esse entendimento ao adicionar a violência cultural ao seu marco teórico. A violência cultural seria definida como os aspectos de uma cultura, ou seja, sua esfera simbólica, que podem ser utilizados para legitimar e justificar os outros dois tipos de violência citados (Galtung, 1990). Sendo a paz a ausência ou redução de violência, ao elaborar o entendimento sobre violência, Galtung (1969) também desenvolve de maneira mais completa o conceito de paz. Para ele, haveria duas dimensões nas quais a paz poderia expressar-se: a Paz Negativa e a Paz Positiva. A primeira é referente à ausência de violência direta, também concebida como pessoal/física. Já a paz positiva pressupõe uma condição justa de distribuição de poder e de recursos que supere as desigualdades estruturais persistentes em uma dada sociedade (Galtung, 1969).

A literatura atualmente tem apontado que os Estudos de Paz tradicionais enfatizaram excessivamente a busca pela Paz Negativa e, consequentemente, a redução da violência letal (Ferreira, 2017; Diehl, 2016). Diehl (2016) aponta, por exemplo, que embora os prêmios Nobel cada vez mais premiem indivíduos e organizações engajados em paz positiva, na academia os estudos continuam demasiadamente concentrados nos aspectos da violência direta e da guerra. Por sua vez, Ferreira (2017) mostra que a construção de uma Paz Positiva tem sido negligenciadas devido a um excessivo foco no viés estatocêntrico e na realização da Paz Negativa. O mesmo estudo vai além ao colocar que os estudos convencionais para a paz não refletiram sobre o principal catalisador da violência na América Latina: uma estrutura de opressão e de exclusão social que relega uma massa de jovens à pobreza, e que é legitimada pelo preconceito cultural das elites da sociedade. Foi exatamente nesse contexto de desigualdade que o crime organizado surgiu, potencializando os números da violência direta em uma região pressupostamente em condição de paz (Ferreira, 2017).

Com a retomada dos conceitos de Galtung em perspectiva crítica, especialmente no que se refere à violência estrutural, se torna inevitável a introdução dos estudos sobre desenvolvimento nas pesquisas de Paz (Lawler, 1995). A representação da violência como algo estrutural e estruturante é clara quando se trata do crime organizado na América Latina: uma estrutura marcada por injustiça social trouxe como consequência o aumento da criminalidade em níveis nunca antes vivenciados. Tendo em vista esse contexto, os esforços visando o desenvolvimento apresentam-se como os meios pelos quais as desigualdades e o espiral da violência podem ser superados para que, desse modo, a justiça social e a Paz Positiva possam ser almejadas (Lawler, 1995).

Para Moser (2004: 3) a natureza multifacetada da violência não se caracteriza como um fenômeno estático, principalmente diante dos fenômenos mais recentes, como pós 11 de setembro (com seus medos e inseguranças), globalização, Estados "fracassados", exclusão, pobreza e desigualdade e a violência urbana. Situação essa apresentada por Ferreira (2016: 145), como um aspecto estrutural relevante diante do contexto latino-americano, na qual a violência direta presente nessa região, possui uma construção social liderada por forças armadas coercitivas, modelos culturais de perpetuação do preconceito, e às mazelas da desigualdade social.

Lançada em 2015, a Agenda 2030 da ONU surge como uma proposta de caráter ousado que tem em seu cerne concepções que compartilham dos ideais de Galtung no que se refere à superação das desigualdades, pois passou a ser um dos principais caminhos para o Desenvolvimento Sustentável concebidos através de políticas e cooperação internacional. O

Estudios de la Paz y el Conflicto, Revista Latinoamericana, IUDPAS-UNAH, Volumen 1, Número 1, enero-junio 2020, pp. 74-96. DOI: 10.5377/rlpc.v1i1.9517 
desenvolvimento sustentável e a governança exigem o (re)estabelecimento de autoridade política legítima, de nível local a estatal, a fim de criar ordens sociais pacíficas que superem as violências. Por outro lado, construir sociedades pacíficas é uma condição para o desenvolvimento econômico e social. Conforme elaborado por Amartya Sen (2010), não sofrer de privação fundamental - como violência ou discriminação - é um ponto de partida essencial para que os indivíduos percebam e desenvolvam plenamente suas capacidades. Este conceito é incorporado nos Objetivos de Desenvolvimento Sustentável (ODS) e enfatizado no ODS16 "Paz, Justiça e Instituições Fortes”.

Logo, além de sua importância inata, a Agenda também representa avanços nos debates dos estudos para a paz ao reconhecer a importância do combate ao crime organizado entre os seus objetivos. Ao trazer o crime organizado como uma verdadeira ameaça à paz, a Agenda corrobora com as abordagens dos Estudos Críticos de Paz e torna-se um poderoso passo para a superação de tal problema ao conectar violência e desenvolvimento social.

\section{OBJETIVOS DO DESENVOLVIMENTO SUSTENTÁVEL: A META 16.}

A agenda 2030 com os Objetivos do Desenvolvimento Sustentável, publicada pelas Nações Unidas, é divulgada em 2015 em forma de um plano de ação paras as pessoas, o planeta e a prosperidade, buscando também fortalecer a paz universal com mais liberdade (ONU, 2015). A Agenda objetiva que todos os países e partes interessadas, de forma colaborativa, consigam implementar esse plano. Dessa forma, surgem 17 Objetivos de Desenvolvimento Sustentável e 169 metas que, segundo a ONU, demonstram a ambição desse novo pacto universal.

Através do legado dos Objetivos de Desenvolvimento do Milênio publicados em 2000, esta nova agenda busca alcançar o que não fora concluído anteriormente. As novas metas e objetivos são pautados em ações para os próximos 15 anos em áreas de relevância para a humanidade, sendo cinco temas centrais nomeados no preâmbulo da Agenda 2030: Pessoas, Planeta, Prosperidade, Paz e Parcerias. Neste artigo, damos especial destaque à Paz e ao enfoque da promoção de sociedades pacíficas, justas e inclusivas, que se tornam livres do medo da violência.

É através do Objetivo de Desenvolvimento Sustentável 16, que possui como propósito promover sociedades pacíficas e inclusivas para o desenvolvimento sustentável, que a paz é discutida na Agenda 2030. Ali temos a proposição de uma agenda de cunho multilateral e de nível mundial que claramente dialoga com os Estudos Críticos de Paz ao sugerir não só uma paz negativa, mas a construção de uma paz positiva (ver Galtung, 1969).

Vorrath e Beisheim (2015: 1), em seu relatório sobre os Objetivos de Desenvolvimento do Milênio, publicado em 2015, indicaram a relevância de questões levantadas pelo ODS 16 ao identificar que conflitos violentos se caracterizam como uma das maiores ameaças ao desenvolvimento humano e um obstáculo central para a implementação dos Objetivos. Os Estados frágeis e em conflito seriam os mais afetados, que por sua vez apresentariam os maiores desafios aos organismos internacionais.

Aqui, vale salientar que ao pressupor como objetivo "promover sociedades pacíficas e justas", o ODS 16 acaba por ter uma relação direta com um dos órgãos máximos da Organização das Nações Unidas: o Conselho de Segurança (CS-ONU). Em sua função de zelar pela paz e pela segurança internacional, este órgão detém um papel central na prevenção, mitigação, resolução e transformação de conflitos que ameacem a paz mundial. No entanto, é igualmente verdade que o CS-ONU tem uma estrutura que não responde aos

Estudios de la Paz y el Conflicto, Revista Latinoamericana, IUDPAS-UNAH, Volumen 1, Número 1, enero-junio 2020, pp. 74-96. DOI: 10.5377/rlpc.v1i1.9517 
problemas de segurança do século XXI - tais como tráfico de pessoas, armas e drogas, ou mesmo terrorismo - haja vista que foi construído em um mundo que vivenciava os horrores da II Guerra Mundial. Por fim, o CS-ONU conta com uma estrutura que mantém os centros de poder do século XX, na qual o poder de veto de cinco membros (China, Rússia, EUA, Reino Unido e França) se sobrepõem muitas vezes ao interesse social pela paz.

Não obstante, este é somente um aspecto do ODS 16. Em sua amplitude e complexidade, ele também prevê a construção de "instituições eficazes, responsáveis e inclusivas" que promovam o Estado de Direito com participação social não discriminatória (ONU, 2015, $\S 16)$. Aqui, a política internacional e suas organizações multilaterais e regionais podem contribuir com uma enormidade de aportes.

Um exemplo seria o Escritório das Nações Unidas para Drogas e Crimes (UNODC). Ainda que este receba críticas por conta de um possível fomento a uma abordagem repressiva quanto ao tráfico de drogas, por outro lado é inegável a importância desta agência da ONU na cooperação internacional para o combate ao crime em suas mais diferentes modalidades. Estão dentro do escopo da UNODC o combate ao tráfico de pessoas, de armas, de drogas, de órgãos e a prevenção da violência criminal e homicida. Assim, diante do ODS 16, a UNODC pode guardar uma importância fundamental em facilitar a cooperação e a capacidade dos Estados-membros da ONU para enfraquecer essas ameaças à paz negativa e positiva.

Entra em jogo aqui também o papel dos organismos regionais. Os debates sobre o ODS 16 nestes organismos são centrais o alcance das metas da Agenda 2030, dado que "o ODS 16 não pode ser alcançado por uma simples comunidade ou grupo", haja vista que "governos nacionais terão um grande impacto [no ODS 16], porém muitos atores serão importantes para dar um salto adiante para alcançar esse objetivo" (Whaites, 2016: 10). Dentre estes atores, uma efetiva cooperação regional torna-se central (Edwards e Romero, 2014; Kim, 2016; Schiano, Chelbly e Ruiz, 2017).

Ao analisarmos especificamente o ODS 16.4 - reduzir significativamente até 2030 os fluxos financeiros e de armas ilegais, reforçar a recuperação e devolução de recursos roubados e combater todas as formas de crime organizado - temos como enfoque o Crime Organizado Transnacional como uma ameaça à Paz. Segundo Whaites (2016: 4) vivenciamos um problema crescente de atores transnacionais e facilitadores de "governanças alternativas", sendo o crime organizado estabelecido cada vez mais facilmente em comunidades locais.

Diante do cenário apresentado como um possível condutor para o crime organizado transnacional, faz se necessário compreender os avanços possibilitados pelo ODS 16.4 para os Estudos para a Paz ao reconhecer a importância da cooperação no combate ao crime organizado. Para Whaites (2016: 7), seria necessário seguir 4 trilhos essenciais para a mudança dessa trajetória, como 1) agir politicamente, percebendo às organizações de desenvolvimento como uma extensão dos interessados; 2) inovar radicalmente, sendo o desenvolvimento institucional implementado factível para acelerar mudanças; 3) mensurar efetivamente os progressos de instituições, e colaborar de forma diferente; e 4) o ODS 16 não deve ser entregue por uma única comunidade, se faz necessário outros atores importantes para alavancar e alcançar o objetivo.

Com estas premissas, torna-se fundamental a compreensão do cenário atual latinoamericano, marcado por uma rede de violência direta, cultural e estrutural que é promovida pela atuação de grupos criminosos nas periferias e nos grandes centros. Como se notará, a problemática da América Latina demanda necessariamente cooperação regional, dado que é praticamente impossível lidar com redes transnacionais complexas somente com políticas públicas domésticas.

Estudios de la Paz y el Conflicto, Revista Latinoamericana, IUDPAS-UNAH, Volumen 1, Número 1, enero-junio 2020, pp. 74-96. DOI: 10.5377/rlpc.v1i1.9517 


\section{CRIME ORGANIZADO, DESENVOLVIMENTO, VIOLÊNCIA E O ODS 16.4}

A atuação do Crime Organizado na América Latina e seu impacto nos números da violência da região podem ser melhor compreendidos a partir da revisão do conceito de Atores NãoEstatais Violentos (ANEVs). Williams (2008) defende que, ano após ano, esses atores vêm se tornando um dos principais desafios aos Estados, pois ameaçam a premissa de que o monopólio do uso da força seria uma incumbência das estruturas estatais. $\mathrm{O}$ autor ressalta que, apesar de apresentarem diferentes formas, esses ANEVs compartilham características em comum que representam um verdadeiro obstáculo à segurança nacional e internacional.

Embora sempre tenham sido uma realidade, é somente a partir do século XXI que os ANEVs surgem como um dos principais desafiadores da ordem Westfaliana, em grande medida, devido à fraqueza de vários Estados e à capacidade de organização e comunicação que o avanço tecnológico possibilitou (Williams, 2008). Contudo, eles não só se apresentam como frutos da fraqueza estatal, como também são grandes responsáveis por perpetuar e intensificar essa condição. Outro importante fator para a compreensão do surgimento dos ANEVs é o fenômeno da globalização. Isso se deve, principalmente, ao desafio que esse fenômeno impõe à capacidade dos Estados de lidarem com problemas que extrapolam as suas fronteiras (Williams, 2008). Dessa forma, os lucros advindos do surgimento de uma economia global ilícita, facilitados pelas novas tecnologias de comunicação e de transporte, sobrepujaram o controle do Estado, tornando-se um incentivo e uma alternativa de financiamento para os ANEVs.

Segundo Phil Williams (2008: 4), os ANEVs são entidades que desafiam o "monopólio do Estado quanto ao uso da violência dentro de um território geográfico específico". Dentre esses grupos, alguns emergem em resposta direta à autoridade do Estado - como insurgentes, rebeldes ou grupos guerrilheiros - enquanto outros se levantam em resposta às oportunidades sistêmicas oferecidas pela fragmentação da autoridade estatal em diferentes níveis de governança, como grupos paramilitares, gangues juvenis e o crime organizado.

Ainda que haja algumas divergências sobre os tipos de ANEVs, há também um consenso na literatura de que as organizações criminosas se configuram claramente como um tipo de ator não-estatal violento (Ezrow, 2017). Aproveitando-se do surgimento de economias globais ilícitas, as organizações criminosas são atualmente as principais responsáveis pelos fluxos de tráfico de drogas, de armas e de pessoas e pelo número crescente de mortes violentas (Ferreira, 2017). A Convenção da Organização das Nações Unidas contra o crime organizado (como citado em Ferreira, 2017) define uma organização criminosa como um grupo estruturado de pessoas que existe por um período de tempo e que atua em conjunto com o objetivo de cometer crimes graves para obter benefícios materiais ou financeiros de forma direta ou indireta.

Segundo Ferreira (2019), alguns desses grupos criminosos não mais atuam apenas domesticamente, tendo alcançado dimensões transnacionais. Tal fato, segundo o relatório do United Nations Office on Drugs and Crime (UNODC), seria consequência de um processo de descentralização do crime organizado:

"Embora ainda existam alguns grupos altamente hierárquicos, as redes estão emergindo como estruturas organizacionais mais flexíveis e eficazes para a perpetração do crime. Essa evolução pode ser vista na maneira como grupos tradicionais [...] tipicamente com uma hierarquia rígida e com um modelo de negócios baseado na exploração e controle de seu território local, expandiram

Estudios de la Paz y el Conflicto, Revista Latinoamericana, IUDPAS-UNAH, Volumen 1, Número 1, enero-junio 2020, pp. 74-96. DOI: 10.5377/rlpc.v1i1.9517 
suas atividades para o tráfico transnacional e passaram a estruturas mais flexíveis, para não perder novas oportunidades" (UNODC, 2019: 41, tradução nossa).

No contexto da América Latina, esses grupos agem em cooperação de tal forma que organizações criminosas de diferentes países operam o tráfico de drogas e realizam ações violentas para além do território estatal de origem.

Por ser um fenômeno multifacetado, a violência do crime organizado seria fruto de uma correlação complexa entre diversos fatores. Porém, dentre esses fatores, a desigualdade de renda apresenta notável relevância, à luz do que já indicava Galtung (1969). Embora o nível de renda per capita, ou seja, a pobreza em si não seja um determinante significativo, os países que apresentam distribuição de renda mais desigual tendem a ter maiores taxas criminais que aqueles com modelos mais igualitários (Heinemann e Verner, 2006). Essas afirmações elucidam as taxas anormais da violência nos países latino-americanos, uma região que foi marcada pelo crescimento desigual.

De maneira ampla, a Organização Pan-Americana de Saúde destacou que a violência promovida pelo crime organizado atuante na América Latina alcançou o status de "pandemia regional" (como citado em Heinemann e Verner, 2006: 2). Isso é demonstrado nos índices de homicídio da região, um retrato do contexto de violência direta vivenciado pelos latinoamericanos diariamente.

Segundo o ranking de 2018 divulgado pela organização mexicana Seguridad, Justicia y $\mathrm{Paz}$ - movimento da sociedade civil que realiza um levantamento anual sobre violência baseando-se em taxas de homicídios por 100 mil habitantes - somente 8 das 50 cidades mais violentas do mundo não se encontram na América Latina. O Instituto Igarapé - ONG com sede no Brasil - complementa a análise através de um levantamento de dados no qual afirma que $37 \%$ dos homicídios do planeta ocorreram na América Latina, apesar da região só concentrar $8 \%$ da população mundial. O levantamento também demonstrou que, desde 2000, mais de 2,5 milhões de pessoas foram assassinadas na América Latina (Lissardy, 2019.) Entretanto, de acordo com a análise sobre homicídios do UNODC, esse cenário de violência não poderia ser explicado somente pelos problemas econômicos que assolam a região, o que reforça a tese de que o crime organizado seria '[...] o fator 'oculto' que eleva a taxa de homicídios a valores mais altos do que o que se esperaria do nível de desigualdade e desenvolvimento socioeconômico de um país" (UNODC, 2019: 44, tradução nossa). A violência resultante da atuação do crime organizado está relacionada à forma como esses grupos estruturam seus negócios: para garantir monopólio, organizações criminosas precisam responder com violência àqueles que desafiam sua autoridade e, uma vez estabelecidos, qualquer ameaça à balança de poder na qual funcionam seus mercados também torna-se um gerador de violência (UNODC, 2019).

Como visto, essa violência é um produto direto da atuação do crime organizado na região. Entretanto, além de existir uma variação na forma em que os países são afetados pela ação desses grupos criminosos, também existem disparidades no modo em que os cidadãos são impactados por esse cenário: evidências nos níveis locais indicam que aqueles que sofrem de exclusão social, econômica e cultural, como indígenas e negros, são desproporcionalmente afetados pela violência, sendo estes os cooptados para o crime, como também os que figuram nas estatísticas dos homicídios, enquanto os cidadãos de renda média são mais afetados por crimes de propriedade.

O relatório da UNODC (2019) vai além e considera elementos demográficos - como gênero e idade - fatores verdadeiramente correlatos às dinâmicas de homicídio ao redor do

Estudios de la Paz y el Conflicto, Revista Latinoamericana, IUDPAS-UNAH, Volumen 1, Número 1, enero-junio 2020, pp. 74-96. DOI: 10.5377/rlpc.v1i1.9517 
mundo. Para o escritório da ONU, "eles podem conduzir certos tipos de homicídios e atuar como fatores de proteção contra outros tipos" (UNODC, 2019: 9, tradução nossa). A realidade da América Latina é um exemplo de tal relação. Em termos de idade e gênero, os homens jovens são os mais afetados pela violência latino-americana e isso pode ser explicado devido ao alto número de jovens abaixo dos 29 anos que se enquadram nas estatísticas dos que nem trabalham e nem estudam. A taxa de homicídios entre essa faixa da população é alta, já que "constituem uma geração inteira de jovens em risco de exclusão social e sem oportunidades, recursos e acesso a mercados de trabalho formais", que acaba sendo atraída pelo mundo do crime organizado. (UNODC, 2019: 11, tradução nossa).

\section{Custos da violência na América Latina para o desenvolvimento da região}

A busca pelo controle da violência que assola a América Latina acaba diminuindo os investimentos voltados para o desenvolvimento da região causando um efeito cíclico: a violência leva a deterioração da economia e isto gera novos surtos de violência (Heinemann e Verner, 2006). Em resumo, toda essa violência tem um custo enorme para a região latinoamericana, já que uma fatia significativa dos recursos estatais, empresariais e individuais são destinados ao gerenciamento do problema, visando trazer um mínimo de segurança para o dia-a-dia (Moser e Mcilwaine, 2006; Jaitman, et al , 2017).

Economicamente falando, para Heinemann e Verner (2006), "evidências mostram que a violência enfraquece consistentemente os esforços de desenvolvimento em vários níveis e impulsiona a depreciação de todas as formas de capital" (2006: 7). A América Latina, em especial, tende a desviar recursos de outros propósitos, como a educação e a saúde, devido a alta incidência da violência. Em termos monetários, segundo relatório do BID (Banco Interamericano de Desenvolvimento) toda a região destina uma média de 3\% do seu PIB a custos relacionados ao crime, isso representa um total de US\$ 174 bilhões ou aproximadamente US\$ 300 per capita. Esse custo pode ser dividido sendo composto $37 \%$ de custos privados, $42 \%$ de despesas públicas e $21 \%$ de custos sociais (Jaitman et al, 2017). Tratando somente dos dispêndios públicos, os dados do BID demonstram que, em valores nominais, os gastos dos governos latino-americanos com o crime somaram entre US\$ 44 bilhões e US\$ 70 bilhões em 2014 (Jaitman, et al, 2017). De maneira ilustrativa, "o gasto governamental devido ao crime representa cerca de um terço das quantias despendidas com educação e saúde".

Ademais, "em uma comparação internacional, o gasto com segurança representa uma proporção mais alta da despesa total do que nos países desenvolvidos" (Jaitman, et al, 2017: 28). Fala-se com frequência que a falta de investimentos em segurança é um dos motores da violência latino-americana, no entanto, a quantia gasta com segurança em relação ao total de gastos públicos da região é quase o dobro da média do mundo desenvolvido (Lissardy, 2019), como mostra o gráfico abaixo sobre a média das porcentagens do PIB dos países latinoamericanos gasto com o crime em relação aos países desenvolvidos.

Estudios de la Paz y el Conflicto, Revista Latinoamericana, IUDPAS-UNAH, Volumen 1, Número 1, enero-junio 2020, pp. 74-96. DOI: 10.5377/rlpc.v1i1.9517 
Figura 1 - Custos Medianos do Crime em Comparação Internacional

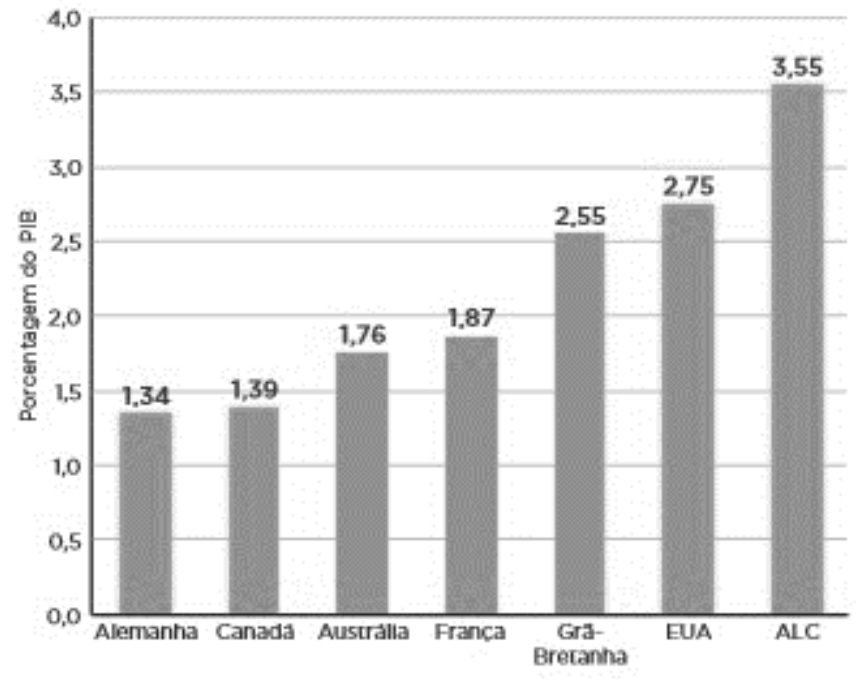

Fonte: Jaitman, 2017.

Quando nos referimos especificamente aos homicídios gerados pela atuação do crime, os custos também são altos. Cerca de US\$ 10 bilhões - de um total de US\$ 16.5 bilhões referentes aos custos dos vitimados por homicídios - são derivados da ação do crime organizado, o que gera impactos no crescimento econômico em um ciclo que propaga a violência, como mostra a imagem a seguir (UNODC, 2019).

\section{Figura 2 - Homicídio e Desenvolvimento Econômico}

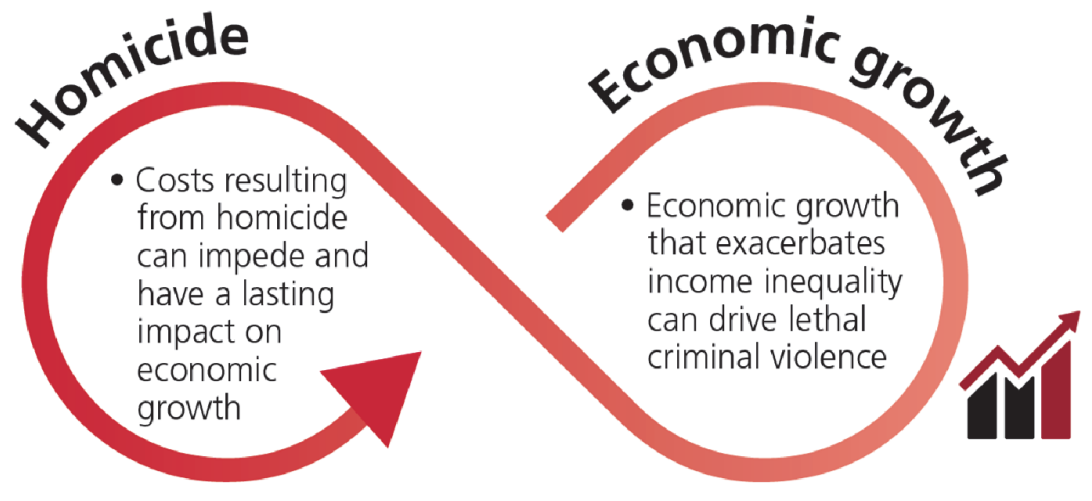

Fonte: Global Study on Homicide, Booklet 4 (UNODC, 2019).

Todavia, indiretamente os homicídios também afetam a nível estrutural as economias latino-americanas, pois diminuem a participação de mão-de-obra jovem no mercado de trabalho, reduzindo a produtividade e a renda das famílias. Em adição, os homicídios derivados do crime também trazem custos não monetários relacionados à saúde mental dos afetados pelo crime, como sobreviventes e parentes da vítima, além do sofrimento psicológico, que resulta em uma redução da qualidade de vida (UNODC, 2019).

Como visto, os custos da violência e, em especial, dos homicídios na América Latina têm impactos diretos na região, pois, em curto prazo afligem o bem-estar humano e no longo 
prazo atingem as perspectivas de um desenvolvimento sustentável para os latino-americanos, no que diz respeito ao crescimento econômico, o desenvolvimento social, a segurança e o Estado de Direto (UNODC, 2019). Todavia, esse processo faz parte de um ciclo vicioso, cujo funcionamento é retroalimentado:

"Como baixos níveis de desenvolvimento [...] podem levar a um ambiente propício ao crime e à violência, o resultado é muitas vezes um círculo vicioso no qual baixos níveis de desenvolvimento estimulam a violência, e a violência diminui ainda mais as oportunidades de desenvolvimento" (UNODC:17, tradução nossa).

Essa relação entre o desenvolvimento sustentável, o crime organizado e a violência tem sido reconhecida pela Agenda 2030, tornando-se central dentro dos debates acerca dos ODS. Entretanto, no caso da América Latina, os caminhos para a superação de um problema que tem dimensões transnacionais perpassam a cooperação dos Estados a nível regional e as Organizações Intergovernamentais são fundamentais para tal, como é o caso da OEA tratado na próxima sessão.

\section{COOPERAÇÃO INTERNACIONAL E A AGENDA 2030: UM OLHAR SOBRE O PAPEL DA OEA}

Diante do cenário latino-americano exposto na seção anterior, no qual o crime organizado se faz cada vez mais presente, é necessário compreender como esse fenômeno é potencializado. Segundo Medeiros (2018), a potencialização se dá por questões de violência estrutural através da pobreza, marginalização e violação básica de direitos humanos. Para Viggiano (2018) compreender a insegurança motivada por instabilidades regionais como aspecto de segurança internacional nos conduz a perceber o impacto que o crime organizado transnacional possui sobre questões de políticas públicas regionais e, por sua vez, como essas podem encontrar amparo em ações de cooperação internacional.

\section{$O$ alinhamento inicial da OEA com o ODS 16.4}

Segundo Ritchie e Ortiz-Ospina (2018), não existem dados e parâmetros claros vinculados ao ODS 16.4. Entretanto, existem dados sobre outros objetivos dentro do ODS 16, como o 16.1, relacionado a redução da violência em todos os lugares, no qual dados sobre homicídios intencionais são apresentados. Essa redução faz referência às taxas globais de homicídios por 100 mil habitantes que diminuiu de 7,2, em 1992 para 6,1, em 2017. Contudo, o número total de homicídios aumentou passando de 400 mil, em 1992 para 460 mil em 2017 - divergência resultante do aumento populacional. No caso latino-americano uma variável central para esse crescimento, como se viu, é o crime organizado transnacional.

Este último fenômeno pode ser considerado um dos mais graves atentados à paz e a segurança internacional, tendendo cada vez mais a demandar ações de cooperação no âmbito internacional. Compreender a insegurança motivada por instabilidades regionais como aspecto de segurança internacional nos conduz a perceber o impacto que o crime organizado transnacional possui sobre questões de políticas públicas regionais e, por sua vez, como essas podem encontrar amparo em ações de cooperação internacional (Viggiano, 2018). Emerge aqui, segundo Medeiros (2018), a colocação em prática dos elementos afirmados na Declaração sobre Segurança nas Américas da Organização dos Estados Americanos (OEA)

Estudios de la Paz y el Conflicto, Revista Latinoamericana, IUDPAS-UNAH, Volumen 1, Número 1, enero-junio 2020, pp. 74-96. DOI: 10.5377/rlpc.v1i1.9517 
quando lembra que "as novas ameaças, preocupações e outros desafios à segurança hemisférica são problemas intersetoriais que requerem respostas de aspectos múltiplos por parte de diversas organizações nacionais e, em alguns casos, associações entre os governos, o setor privado e a sociedade civil" (como citado em OEA, 2003: 2).

Após a divulgação da Agenda 2030 e dos 17 Objetivos de Desenvolvimento Sustentável em 2015, percebe-se um alinhamento inicial entre a Organização dos Estados Americanos (OEA) e os ODS como uma questão relevante para a segurança regional. Na Assembleia Geral da OEA em 2016, temos a primeira citação direta sobre os ODS, no qual um Programa Interamericano de Desenvolvimento Sustentável (PIDS) é criado para estabelecer estratégias de ação para assegurar que o trabalho da Secretaria Geral de Desenvolvimento Sustentável esteja alinhado com a implementação nas Américas da Agenda 2030 e que seus objetivos e resultados estejam guiados pelos ODS aprovados pelos Estados membros (OEA, 2016).

O PIDS surge como um fortalecimento entre a OEA e os ODS, citando os Objetivos que passam a ser o foco do programa. O ODS 16 é nomeadamente citado como um dos parâmetros, mas com enfoque nas instituições efetivas e inclusivas em todos os níveis. No mesmo ano, os Objetivos de Desenvolvimento são citados como uma forma de fortalecer o Conselho Interamericano de Desenvolvimento Integral (CIDI), ao buscar um diálogo político com o intuito de produzir parcerias de cooperação para o desenvolvimento (OEA, 2016). Dentre os documentos coletados datados no ano de 2015, temos o Relatório da Secretaria Multidimensional sobre a Implementação do Plano Hemisférico de Ação Contra a Criminalidade Organizada Transnacional, sendo uma ação do Conselho Permanente da OEA, e relatado pela Comissão de Segurança Hemisférica. O Plano Hemisférico foi aprovado pelo Conselho Permanente da OEA ainda em 2006, esboçando uma série de ações destinadas a intensificar a cooperação nas áreas de prevenção e investigação da criminalidade organizada transnacional, mas também com relação a respectiva ação penal e decisões judiciais a ela relacionadas, bem como um fortalecimento da capacidade e competência nacional, subregional e regional. O relatório detalha as atividades da Secretaria de Segurança Multidimensional e seus órgãos auxiliares, a Secretária Executiva da Comissão Interamericana para o Controle do Abuso de Drogas; Secretaria Executiva do Comitê Interamericano contra o Terrorismo; e o Departamento de Segurança Pública (DSS).

Dentre as estratégias nacionais apresentadas para combater a criminalidade organizada transnacional se tem a prevenção a esse fenômeno, sendo apresentado em 2012 o desenvolvimento de um "Modelo para Fortalecer a Capacidade Institucional de Abordar as Preocupações de Segurança Cidadã” pela Secretaria de Segurança Multidimensional (SSM) da OEA. Esta tem como objetivo oferecer uma visão ampla da segurança cidadã em um determinado país mediante a análise dos pontos fortes e deficientes dos seguintes subsistemas: Ministério da Segurança; Polícia Nacional; Sistema Carcerário; Poder Judiciário; Ministério Público; Segurança Privada; e Parlamento. Em linha com este modelo, de 2012 a 2014, a pedido de cada governo, a Secretaria procedeu a avaliação de necessidades em Honduras, El Salvador, Costa Rica e Belize.

Quanto às estratégias relacionadas aos Instrumentos Jurídicos, a Secretária de Segurança Multidimensional promoveu, quando oportuno, a implementação de ações pontuais, especialmente a Convenção das Nações Unidas contra o Crime Organizado Transnacional; o Protocolo para Prevenir, Suprimir e Punir o Tráfico de Pessoas; Protocolo contra a Fabricação e o Tráfico Ilícito de Armas de Fogo a Convenção das Nações Unidas contra o Tráfíco Ilícito de Entorpecentes e Substâncias Psicotrópicas; a Convenção Interamericana contra a Fabricação e o Tráfico Ilícitos de Armas de Fogo, Munições, Explosivos e Outros Materiais

Estudios de la Paz y el Conflicto, Revista Latinoamericana, IUDPAS-UNAH, Volumen 1, Número 1, enero-junio 2020, pp. 74-96. DOI: 10.5377/rlpc.v1i1.9517 
Correlatos (CIFTA). Assim, ações de divulgação e promoção do uso de ferramentas para apoiar a assinatura, ratificação e implementação dos elementos constantes dessas leis, teve por objetivo promover respostas e ajustes nacionais contra a criminalidade organizada, por meio do Departamento de Segurança Pública, Secretaria Executiva da Comissão Interamericana para o Controle do Abuso de Drogas (CICAD) e da Secretaria de Segurança Multidimensional.

Assuntos relativos à execução de lei também passam a ser o foco do DSP no sentido de enfrentar os impactos da violência relacionada a criminalidade e fortalecer as instituições nacionais responsáveis pela assistência e proteção de vítimas desses crimes em países como Guatemala, Honduras e El Salvador. Posteriormente, o projeto foi estendido para Costa Rica, Panamá, Nicarágua, República Dominicana e Belize. Foi também objetivo do DSP desenvolver um novo código de ética policial, aplicando na polícia nacional do Uruguai o programa "Gestão Local Integrada da Segurança Cidadã", em implementação pelo Governo do Uruguai e Banco Interamericano de Desenvolvimento (BID). O DSP igualmente organizou uma Rede Interamericana de Desenvolvimento e Profissionalização Policial, com vistas de contribuir de maneira permanente para o fortalecimento do profissionalismo das instituições policiais dos Estados membros. Em 2014, reuniões técnicas ocorreram com os parceiros estratégicos do programa, entre eles a Polícia Federal do Brasil, sendo o primeiro curso desenvolvido em 2015.

Com relação a 2016, destaca-se o Grupo de Trabalho (GT) da Comissão de Segurança Hemisférica sobre o Plano de Ação Hemisférico contra a Criminalidade Organizada Transnacional. Este GT levanta que o fenômeno do crime descrito requer a avaliação das estruturas e mecanismos de coordenação e cooperação hemisférica já existentes na OEA, que por sua vez possibilitem uma resposta rápida e efetiva aos novos desafios provocados pela criminalidade organizada transnacional. Para isso, diz ser necessária uma possível revisão da efetividade do Plano de Ação Hemisférico, e caso pertinente, sua atualização. Com isto em mente é criado um Grupo de Trabalho encarregado de avaliar a implementação do Plano de Ação Hemisférico contra a Criminalidade Organizada Transnacional, e de assim solicitar a Secretaria Geral o apoio técnico e administrativo necessário para que a missão seja cumprida. No mesmo ano, temos um questionário de avaliação do Nível de Implementação do Plano de Ação Hemisférico Contra a Criminalidade Organizada Transnacional, publicado em abril, e apresentado pelo Grupo de Trabalho citado anteriormente. Passados nove anos desde a aprovação do Plano de Ação Hemisférico, fazia-se necessário conhecer a situação atual dos Estados membros com relação a implementação das ações, determinando assim o quanto influenciou às leis e os sistemas normativos nos Estados (OEA, 2016). Com relação aos instrumentos jurídicos, temos como questionamento a assinatura e ratificação do país em determinados acordos internacionais, como a Convenção das Nações Unidas contra o Crime Organizado Transnacional (2000) e o Protocolo contra a Fabricação e o Tráfico Ilícitos de Armas de Fogo, suas Peças e Componentes e Munições (2000).

As respostas ao questionário somente são publicadas em novembro de 2016. Em virtude do número de questionários respondidos, a SSM considerou que no momento não dispõe de informação suficiente que possibilite levar adiante a análise técnica com um nível necessário de detalhamento para assim oferecer aos Estados membros uma visão completa da situação. A falta da colaboração estatal indica aqui a fragilidade regional para a consecução da meta 16.4 da Agenda 2030. Tem sido comum no âmbito das Américas o fortalecimento de medidas de confiança mútua, muito também por conta da pretensa parcialidade da OEA em assuntos sensíveis na região como as mudanças institucionais à margem da democracia, tais como

Estudios de la Paz y el Conflicto, Revista Latinoamericana, IUDPAS-UNAH, Volumen 1, Número 1, enero-junio 2020, pp. 74-96. DOI: 10.5377/rlpc.v1i1.9517 
ocorrido em Honduras em 2009 e recentemente na Bolívia em novembro de 2019. Não obstante os significativos obstáculos políticos, passos importantes foram dados em âmbito institucional, como veremos na seção a seguir.

\section{Surgimento do Departamento contra o Crime Organizado Transnacional (DCOT) e seu potencial como catalisador da cooperação em prol do ODS 16.4}

Na Assembleia Geral da OEA de 2016, em uma das resoluções nomeada de Avançando na Segurança do Hemisfério: uma abordagem multidimensional, são recordadas resoluções assinadas pela Comissão de Segurança Hemisférica, principalmente a resolução referente às Américas como uma zona de paz, cooperação e solução pacífica de controvérsias, reiterando os esforços para combater as ameaças à paz e segurança, e os crimes transnacionais que ameaçam a segurança pública do Estados membros. Não obstante a falácia que é a afirmação de que as Américas é uma zona de paz, tal como debatido na literatura (Rodrigues, 2019; Ferreira, 2017), temos aqui como ponto positivo o reconhecimento dos esforços do grupo de trabalho da Ação Hemisférica contra o Crime Organizado Transnacional, tido como uma ameaça à paz social na região.

Dali surge um importante passo, que é a criação do Departamento contra o Crime Organizado Transnacional (DCOT) pela Secretaria Geral da OEA. O departamento é criado pela Secretaria Geral como parte da reestruturação da Secretaria de Segurança Multidimensional e parte de sua modernização e reorganização. O propósito do DCOT é coordenar todos os esforços da Secretária Geral para fortalecer as capacidades institucionais e políticas públicas para confrontar e responder às diversas manifestações do Crime Organizado Transnacional, incluindo lavagem de dinheiro, tráfico ilícito de drogas, contrabando relacionado, tráfico de armas de fogos e correlatos. Em novembro de 2019 foi nomeado como diretor do DCOT o argentino Gastón Schulmeister, que antes atuava como Diretor de Cooperação Internacional no Ministério de Segurança do seu país.

Em fevereiro de 2017, o Conselho Permanente divulgou uma proposta de sessão conjunta do Conselho Permanente e do Conselho Interamericano de Desenvolvimento Integral sobre a promoção dos ODS nos Estados Membros da OEA, no qual possui como premissa a ideia de que, tendo a Agenda 2030 um escopo ambicioso, não pode ser cumprida por qualquer governo ou parceiro de desenvolvimento isoladamente.

Ainda no mesmo ano, temos na Assembleia Geral a reafirmação das publicações da carta da OEA nos aspectos relacionados ao desenvolvimento econômico, social e cultural, assim como na erradicação da pobreza extrema. Esta última é tida como um obstáculo para o pleno desenvolvimento democrático do hemisfério, em linha do que se preconiza na ideia de paz positiva. Na mesma ocasião, reforça-se que o trabalho da OEA, no pilar do desenvolvimento, é governado por um Plano Estratégico da Organização, adotado pela Assembleia Geral e que está alinhado com as contribuições da implementação da Agenda 2030 e com os ODS, com relação a sua estrutura geral de ação.

Em 2018 há um Projeto de Resolução, nomeado de Promoção da Segurança Hemisférica. O Projeto tem um enfoque multidimensional, datado de maio de 2018, e publicado pela Comissão de Segurança Hemisférica. Este projeto busca continuar o trabalho de consolidar as Américas como zona de paz, convidando a Comissão de Segurança Hemisférica para que, no segundo semestre de 2018, promova uma aproximação com a Comissão de Consolidação da Paz das Nações Unidas. No quesito Combate à Criminalidade Organizada Transnacional, insta os Estados membros a entregarem os questionários sobre a implementação do Plano de

Estudios de la Paz y el Conflicto, Revista Latinoamericana, IUDPAS-UNAH, Volumen 1, Número 1, enero-junio 2020, pp. 74-96. DOI: 10.5377/rlpc.v1i1.9517 
Ação Hemisférico contra a delinquência organizada transnacional. Ainda, solicita que o DCOT conclua a análise dos questionários e elabore o Relatório Final para ser apresentada ao CSH no segundo semestre de 2018, juntamente com as propostas apresentadas pelos Estados membros para aperfeiçoar o Plano de Ação. Assim, o projeto apoia o DCOT e insta que lhe sejam destinados os recursos humanos e financeiros necessários ao seu funcionamento eficaz, respeitando a necessidade orçamentária, e solicitando que os Estados membros considerem designar especialistas em DOT para trabalhar no DCOT.

O projeto também solicita que o DCOT continue oferecendo assistência técnica aos países membros da OEA - que o solicitarem - que encontraram novas ameaças em zonas fronteiriças, com o objetivo de incentivar a implementação da Convenção das Nações Unidas contra o Crime Organizado Transnacional (UNCTOC), e o Plano de Ação Hemisférico. Aqui se nota uma disfunção do DCOT desde seu início, pois considera as zonas fronteiriças como ameaças. Na verdade, no cerne dos Estudos de Paz está a ideia de que há muitas linhas de fronteira cortando a humanidade, criando diferentes graus na integração e no desejo de utilizar a violência; mas somente algumas dessas linhas são fronteiras nacionais (Galtung, 1964). Ou seja, a promoção do objetivo 16.4 da Agenda 2030, institucionalizado no DCOT, traz em si uma percepção inicial errônea de que o estabelecimento da paz e desenvolvimento passa por criminalizar fronteiras, tidas aqui como "ameaças".

Ademais, os Estados membros são convidados a desenvolverem e implementarem políticas interinstitucionais que os permitam renovar o compromisso de cooperação jurídica internacional, com o objetivo de que os Ministérios Públicos e às Procuradorias Gerais dos Estados compartilhem boas práticas e estratégias de investigação, e assim promover intercâmbios de informações que permitam neutralizar as estruturas financeiras dessas organizações criminosas. Assim, o projeto convoca os Estados membros, organismos regionais e internacionais a realizarem contribuições voluntárias para o Fundo contra a Criminalidade Organizada Transnacional, previsto no Plano de Ação Hemisférica. Tal fundo pode ser um importante passo para o objetivo 16.4, desde que supere os problemas anteriormente apontados de parcialidade política e concepção repressiva da ideia de fronteira. Ainda em 2018, na resolução "Avançando na Segurança Hemisférica: uma abordagem multidimensional", temos uma reafirmação do comprometimento da Organização dos Estados Americanos de fortalecer a paz e a segurança no hemisfério, com total respeito às leis internacionais e em concordância com às leis domésticas de cada país. Dali sai como resultado a ação de um trabalho contínuo para consolidar às Américas como uma zona de paz, considerando a paz como um bem supremo, um valor, e um princípio em si, uma aspiração legítima de todos os povos, e que a prevenção da paz é um elemento substancial de integração e cooperação, baseado no respeito à democracia, justiça, direitos humanos, segurança, e normas do direito internacional (OEA, 2018). Cabe saber se o que é expressado em palavras se transformará em ações em prol da paz positiva.

O combate ao Crime Organizado Transnacional é tido como outra resolução, no qual insta os Estados membros a remeter novas informações, tendo como objetivo corrigir, completar e melhorar as informações fornecidas sobre um sensível tema relacionado com o ODS 16.4. Ainda, requisita que o DCOT prepare um relatório final, que deve ser apresentado ao Conselho de Segurança Hemisférica durante a segunda metade de 2018, e também acompanhar todas as propostas apresentadas pelos Estados membros para melhorar o Plano de Ação.

No final de 2018, é divulgado o Projeto de Agenda para a Reunião de Autoridades Nacionais sobre Criminalidade Organizada Transnacional. Uma das pautas levantadas é com

Estudios de la Paz y el Conflicto, Revista Latinoamericana, IUDPAS-UNAH, Volumen 1, Número 1, enero-junio 2020, pp. 74-96. DOI: 10.5377/rlpc.v1i1.9517 
relação às ameaças atuais e emergentes da COT e medidas de cooperação internacional para enfrentá-las, sendo citada a necessidade de lidar com os vínculos entre corrupção e COT, o potencial uso da inteligência artificial por parte das organizações criminosas transnacionais, o fortalecimento do uso de técnicas especiais de investigação e identificação dos principais desafios operacionais. O México levanta como uma das pautas os esforços regionais em relação aos Objetivos de Desenvolvimento Sustentável:

"Soma de esforços para o cumprimento da meta 16.4, que estabelece "Até 2030, reduzir significativamente os fluxos financeiros e de armas ilegais, reforçar a recuperação e devolução de recursos roubados, e combater todas as formas de crime organizado" (OEA, 2018: 2).

No ano de 2019, em fevereiro, temos a atualização do Projeto de Agenda para a Segunda Reunião de Autoridade Nacionais sobre a Criminalidade Organizada Transnacional. Ali figuram o incremento nas questões a serem enfrentadas no combate a criminalidade organizada transnacional, como o tráfico ilícito de armas pequenas e de drogas como atividade criminosa significativa, e a investigação das organizações criminosas e suas conexões com o sistema penitenciário. No debate da cooperação internacional, ressalta-se a construção de capacidade nas Américas na utilização de técnicas especiais de investigação, troca de experiências com gestão de ativos e sobre o uso de ferramentas e base de dados internacionais. Figura ali também o aprimoramento das medidas de cooperação, através de esforços regionais para o cumprimento da Meta 16 das Nações Unidas para o Desenvolvimento Sustentável, resolução que possui uma alteração no documento de março de 2019, com o objetivo de aprimorar as medidas de cooperação no âmbito do ODS 16.4, especificamente.

Kim (2016) afirma que os ODS devem servir para orquestrar um acordo internacional visando reunir esforços e diferentes elementos organizacionais para alcançar um mesmo objetivo. Quando avaliamos nossa questão inicial - a saber, quais os caminhos de avanço da cooperação internacional promovidos pela Agenda 2030, em seu objetivo 16.4, podem ser verificados a partir da atuação da Organização dos Estados Americanos (OEA)? - pode-se dizer que a cooperação internacional com OEA, o Estado e a Agenda 2030, torna possível alcançar às metas e objetivos traçados pela Agenda. Muitos dos recursos apresentados após 2015 pela OEA com relação ao combate ao crime organizado não possuem menção direta aos ODS, mas representam um alinhamento da organização para com o que foi proposto pelas Nações Unidas, o que demonstra um esforço da mesma para enfrentar problemas que já eram de estudo da organização, não obstante os ainda importantes desafios a serem enfrentados relacionados com o comprometimento dos países membros.

Percebe-se, dessa maneira, uma convocação de uma coordenação maior dentro das instituições e entre elas, tanto de âmbito internacional, como nacional e de governos locais (OEA, 2017). Ainda que ali se justifique que a OEA possua os requisitos para conduzir com eficácia uma colaboração e coordenação no sistema interamericano, também não se pode perder de vista os obstáculos existentes relacionados à percepção do papel da OEA. Levar adiante o diálogo político, a cooperação técnica e o intercâmbio de experiências em todos os ODS demandaria da OEA uma perspectiva mais holística, de respeito às instituições não alinhadas com o modelo de democracia liberal promovido pelos Estados Unidos. Ainda, é fundamental considerar que a construção da paz positiva demanda mais do que meros instrumentos jurídicos internacionais. Lidar com as desigualdades econômicas e políticas e a superação de violências estruturais de natureza continental se faz altamente necessário.

Estudios de la Paz y el Conflicto, Revista Latinoamericana, IUDPAS-UNAH, Volumen 1, Número 1, enero-junio 2020, pp. 74-96. DOI: 10.5377/rlpc.v1i1.9517 
Assim, nota-se que os caminhos dos avanços no plano institucional em prol do ODS 16.4 se deram nos últimos anos com a criação de um plano em prol do desenvolvimento sustentável e do DCOT. Falta agora a parte mais importante: uma concepção política e social que considere a paz positiva de uma maneira mais ampla, holística e em linha com a redução significativa da violência estrutural. A Agenda 2030 é somente uma parte de um processo mais amplo de promoção da paz e desenvolvimento, dado que a paz positiva pressupõe uma condição justa de distribuição de poder político e econômico. Sem lidar com isso, a agenda da OEA será limitada, amparada em boas intenções codificadas no direito internacional, mas sem efeito prático na vida de milhões de latino-americanos que vivem diariamente um vergonhoso cenário de violência direta, estrutural e cultural. Cabe à OEA pensar além: promover a Agenda 2030 e a luta em prol do objetivo 16.4 é só um passo que precisa ser seguido de uma mudança da ordem atual que vê fronteiras como ameaças, repressão como alternativa e desigualdade como externalidade. Só não se sabe, porém, se a organização será capaz de dar este passo além.

\section{Tabela 1 - Documentos analisados da Organização dos Estados Americanos}

\begin{tabular}{|l|l|}
\hline Encontro & Data \\
\hline Assembleia Geral. Volume I. & Junho 2015 \\
\hline $\begin{array}{l}\text { Relatório da Secretaria de Segurança Multidimensional sobre a Implementação } \\
\text { do Plano Hemisférico de Ação contra a Criminalidade Organizada Transnacional. }\end{array}$ & Fevereiro 2015 \\
\hline $\begin{array}{l}\text { Assembleia Geral. } \\
\text { Volume I. }\end{array}$ & Junho 2016 \\
\hline $\begin{array}{l}\text { A Comissão de Segurança Hemisférica do Conselho Permanente da Organização } \\
\text { dos Estados Americanos. }\end{array}$ & Janeiro 2016 \\
\hline $\begin{array}{l}\text { Questionário de Avaliação do Nível de Implementação do Plano de Ação } \\
\text { Hemisférico Contra a Criminalidade Organizada Transnacional }\end{array}$ & Abril 2016 \\
\hline $\begin{array}{l}\text { Observações e Recomendações dos Estados Membros sobre o Relatório Anual da } \\
\text { Comissáo Interamericana para o Controle do Abuso de Drogas (CICAD) ao } \\
\text { quadragésimo sexto período ordinário de sessões da Assembleia Geral }\end{array}$ & Maio 2016 \\
\hline Relatório de Atividades da Comissão de Segurança Hemisférica & Junho 2017 \\
\hline $\begin{array}{l}\text { Relatório da Secretaria de Segurança Multidimensional sobre às Respostas } \\
\text { Recebidas ao Questionário de Avaliaça do Nível de Implementação do Plano de } \\
\text { Ação Hemisférico Contra a Criminalidade Organizada Transnacional. }\end{array}$ & Novembro 2016 \\
\hline \begin{tabular}{l} 
Assembleia Geral. Volume I. \\
\hline
\end{tabular} & \\
\hline
\end{tabular}

Estudios de la Paz y el Conflicto, Revista Latinoamericana, IUDPAS-UNAH, Volumen 1, Número 1, enero-junio 2020, pp. 74-96. DOI: 10.5377/rlpc.v1i1.9517 


\begin{tabular}{|l|l|}
$\begin{array}{l}\text { Proposta de Sessão Conjunta do Conselho Permanente e do Conselho } \\
\text { Interamericano de Desenvolvimento Integral sobre a Promoção dos ODS nos } \\
\text { Estados Membros da OEA: o papel da OEA }\end{array}$ & Fevereiro 2017 \\
\hline Declarações e Resoluções Adotadas pela Assembleia Geral. & Junho 2018 \\
\hline Promoção da Segurança Hemisférica: um enfoque multidimensional. & Maio 2018 \\
\hline $\begin{array}{l}\text { Projeto de Agenda para a Reunião Anual de Autoridades Nacionais sobre a } \\
\text { Criminalidade Organizada Transnacional. }\end{array}$ & Dezembro 2018 \\
\hline $\begin{array}{l}\text { Projeto de Agenda para a Segunda Reunião de Autoridade Nacionais sobre a } \\
\text { Criminalidade Organizada Transnacional. }\end{array}$ & Fevereiro 2019 \\
\hline $\begin{array}{l}\text { Projeto de Calendário da Segunda Reunião de Autoridade Nacionais em Matéria } \\
\text { de Criminalidade Organizada Transnacional }\end{array}$ & Março 2019 \\
\hline Promoção da Segurança Hemisférica: um enfoque multidimensional. & Maio 2019 \\
\hline
\end{tabular}

Fonte: elaboração própria a partir de documentos coletados no site da OEA.

\section{CONCLUSIONES}

A Agenda 2030 das Nações Unidas apresentou um grande avanço ao considerar em seu objetivo 16.4 o combate aos ilícitos transnacionais e crime organizado. Adicionalmente, ao conectá-los com a agenda de desenvolvimento sustentável, permitiu retomar os Estudos de Paz em sua origem. Estes estudos compreendem a paz como a ausência de violência direta e estrutural, sendo esta última aquela conectada com a desigualdade social e injustiças socioeconômicas. Assim, a Agenda 2030 é acertada ao colocar a paz e violência dentro de uma dinâmica multidimensional que caracteriza o fenômeno.

Em particular, o crime organizado que assola países da América Latina em maior ou menor medida, está intimamente conectado com as limitações de desenvolvimento desses Estados. Estudos demonstram que a desigualdade justamente fomenta este crime (Blackwell; Duarte, 2014; Heinemann; Verner, 2006), ao mesmo tempo que este crime reproduz esta desigualdade (Ferreira, 2017).

Nos índices de violência epidêmicos (Cerqueira, et.al, 2019) que a região latinoamericana apresenta, o crime organizado dá uma parcela significativa de contribuição. Aproveitando-se das redes financeiras e comunicacionais facilitadas pela globalização econômica, a criminalidade apresenta-se como um fenômeno dinâmico, transnacional, que não pode ser combatido simplesmente com políticas domésticas.

Emerge então a necessidade fundamental da promoção do ODS 16.4 através da cooperação regional. No caso da América Latina, a OEA apresenta grande potencial de emergir como facilitadora desta cooperação após 2015, tornando-se um baluarte de esperança. Seus avanços em temas relacionados ao ODS 16.4, especialmente com a criação

Estudios de la Paz y el Conflicto, Revista Latinoamericana, IUDPAS-UNAH, Volumen 1, Número 1, enero-junio 2020, pp. 74-96. DOI: 10.5377/rlpc.v1i1.9517 
do Departamento contra o Crime Organizado Transnacional (DCOT) em 2016, trazem um alento para a cooperação regionalizada contra o crime organizado. Cabe ao Estados, assolados por uma violência obscena, absorver as políticas e debates fomentados no âmbito da OEA como resposta ao crime organizado. No entanto, torna-se mister também pensar além, promovendo igualmente a superação da violência estrutural e a diminuição das desigualdades regionais. A Agenda 2030 é só um passo para algo que demanda ainda mais força política e social, a saber, a promoção da paz positiva.

Finalmente, em um mundo interconectado caberá aos países da América Latina compreender a importância que políticas regionais relevantes e debates de alto nível como os promovidos por uma organização consolidada como a OEA. Superar seus problemas e contradições será igualmente necessário em prol de debates e propostas de ações que podem subsidiar políticas públicas no nível doméstico e que permitam coordenação interinstitucional com outros países que vivem o mesmo problema. Caberá aos estudos futuros avaliarem se os países da região e a OEA adotarão uma política aberta ao diálogo e à cooperação, ou se continuaremos a perpetuar a violência com políticas domésticas repressivas e ineficazes que só fazem frear o desenvolvimento sustentável e ameaçarem a paz social.

\section{REFERÊNCIAS}

Blackwell, A., Duarte, P. (2014). "Violence, Crime and Social Exclusion". Em Inequality and Social Exclusion in the Americas: 14 Essays (2 Edição). Washington: Organização dos Estados Americanos (OEA), 111-134.

Cerqueira, D., Lima, R. S., Bueno, S., Neme, C., Ferreira, H., Alves, Palmieri, P., Marques, D., Reis, M., Cypriano, O., Sobral, I., Pacheco, D., Lins, G., Armstrong, K. (2019). Atlas da Violência 2019. São Paulo: Fórum Brasileiro de Segurança Pública.

Diehl, P. (2016). "Exploring Peace: looking beyond war and negative Peace", International Studies Quarterly, Vol. 60, 1-10.

Edwards, M., Romero, S. (2014). "Governance and the Sustainable Development Goals: Changing the Game or More of the Same?", SAIS Review Of International Affairs, Vol. 34, N. 2, 141-150.

Ezrow, N. (2017). Global politics and violent non-state actors. Los Angeles: SAGE.

Ferreira, M. (2019). "Brazilian criminal organizations as transnational violent non-state actors: a case study of the Primeiro Comando da Capital (PCC)", Trends in Organized Crime, N. 22, 148-165. DOI: https://doi.org/10.1007/s12117-018-9354-7.

Ferreira, M. (2016). "Contemporaneidade dos Conceitos de Paz e Violência em Johan Galtung e sua Aplicabilidade para a América do Sul”. Em Winand, E., Rodrigues, T., Aguilar, S., Defesa e Segurança no Atlântico Sul - VIII ENABED (1 Edição). Aracaju: Universidade Federal de Sergipe, Vol.1, 145-160.

Ferreira, M. (2017). "Estudos Críticos da Paz e Crime Organizado Transnacional", Revista Crítica de Ciências Sociais, N. 113, 29-50.

Galtung, J. (1964). "Editorial”, Journal of Peace Research, Vol. 1, N.1, 1-3.

Galtung, J. (1990). "Cultural Violence", Journal of Peace Research, Vol. 27, N. 3, 291-305.

Galtung, J. (1969). "Violence, peace, and peace research", Journal of Peace Research, Vol. 6 , N. 3, 167-191.

Estudios de la Paz y el Conflicto, Revista Latinoamericana, IUDPAS-UNAH, Volumen 1, Número 1, enero-junio 2020, pp. 74-96. DOI: 10.5377/rlpc.v1i1.9517 
Heinemann, A., Verner, D. (2006). "Crime and violence in development: A literature review of Latin America and the Caribbean", Policy Research Working Paper, N. 4041. Washington, DC.: World Bank.

Jaitman, L., Caprirolo, D., Granguillhome Ochoa, R., Keefer, P., Leggett, T., Lewis, J. A., Mejía-Guerra, J. A., Mello, M., Sutton, H., Torre, I. (2017). Os custos do crime e da violência: novas evidências e insights na América Latina e no Caribe. Washington: Banco Interamericano de Desenvolvimento.

Jutila, M., Pehkonen, S., Vayrynen, T. (2008). "Resuscitating a discipline: an agenda for critical peace research", Millennium, Vol. 36, N. 3, 623-640.

Kim, R. (2016). "The Nexus between International Law and the Sustainable Development Goals", Review of European Comparative \& International Environmental Law, Vol. 25, N. 1, 15-26.

Lawler, P. (1995). A Question of Values: Johan Galtung's peace research. Boulder: Lynne Rienner Publishers.

León, B., Tager, A. (2016). "Armed Social Violence and Peacebuilding: Towards an Operation Approach". Em Unger B., Dudouet, V., Dressler, M. e Austin, B. (Eds.), Undeclared wars - Exploring a peacebuilding approach to armed social violence. Berghof: Handbook Dialogue Series, N. 12.

Lissardy, G. (2019). Por que a América Latina é a região mais violenta do mundo. BBC. Disponível online (https://www.bbc.com/portuguese/internacional-48988559) (Consultado em: 15.10.2019)

MacGinty, R. (2019). "Complementarity and Interdisciplinarity in Peace and Conflict Studies", Journal of Global Security Studies, N. 4, Vol. 2, 267-272. DOI: 10.1093/jogss/ogz002.

Medeiros, J. (2018). "Cooperação Bilateral no Combate à Criminalidade Organizada Transnacional: uma análise das ações brasileiro-paraguaias nas regiões de fronteira". 124 f. Dissertação (Mestrado em Gestão Pública e Cooperação Internacional) - CCSA, Universidade Federal da Paraíba, João Pessoa.

Moser, C. (2004). "Urban Violence and Insecurity: an introductory roadmap", Environment e Urbanization, Vol. 16, N.2.

Moser, C.; Mcilwaine, C. (2006). "Latin American urban violence as a development concern: towards a framework for violence reduction", World Development, Vol. 34, N. 1, 89-112. DOI: 10.1016/j.worlddev.2005.07.012.

ONU (Organização das Nações Unidas) (2015). Objetivos do Desenvolvimento Sustentável. 13 de out. 2015. Disponível online (https://nacoesunidas.org/pos2015/agenda2030/) (Consultado em: 25.06.2019).

OEA (Organização dos Estados Americanos) (2013). Convenção da ONU contra Crime Organizado Transnacional Comemora 10 Anos. 21 de Out, 2013. Disponível online (https://nacoesunidas.org/convencao-da-onu-contra-crime-organizado-transnacionalcomemora-10-anos/). (Consultado em: 25.06.2019).

OEA (2015). Assembleia Geral. Volume I. Washington, 2015. Disponível online (http://www.oas.org/en/sla/docs/AG06943E04.pdf) (Consultado em: 30.01.2019).

OEA (2015). Relatório da Secretaria de Segurança Multidimensional sobre a Implementação do Plano Hemisférico de Ação contra a Criminalidade Organizada Transnacional. 2015. Disponível online (http://www.oas.org/es/council/CSH/documentation/var_documents2/). (Consultado em: 30.01.2019).

Estudios de la Paz y el Conflicto, Revista Latinoamericana, IUDPAS-UNAH, Volumen 1, Número 1, enero-junio 2020, pp. 74-96. DOI: 10.5377/rlpc.v1i1.9517 
OEA (2016). Assembleia Geral. Volume I. Santo Domingo, 2016. Disponível online (http://www.oas.org/en/sla/docs/AG07239E03.pdf) (Consultado em: 30.01.2019).

OEA (2017). Assembleia Geral. Volume I. Cancun, 2017. Disponível online (http://www.oas.org/en/sla/docs/AG07524E02.pdf) (Consultado em: 30.01.2019).

OEA (2017). Proposta de Sessão Conjunta do Conselho Permanente e do Conselho Interamericano de Desenvolvimento Integral sobre a Promoção dos ODSs no Estados Membros da OEA: o papel da OEA. 2017. Disponível online (http://www.oas.org/es/council/CP/documentation/var documents/cpinf/). (Consultado em: 30.01.2019).

OEA (2018). Declarações e Resoluções Adotadas pela Assembleia Geral. Washington, 2018. Disponível online ( http://www.oas.org/en/sla/docs/AG07691E07.pdf) (Consultado em: 30.01.2019).

Pureza, J. M., Cravo, T. (2005). "Margem crítica e legitimação nos estudos para a paz", Revista Crítica de Ciências Sociais, N. 71, 5-19. DOI: 10.4000/rccs.1011.

Ritchie, H., Roser, M., Mispy, J., Ortiz-Ospina, E. (2018). "Measuring progress towards the Sustainable Development Goals". SDG-Tracker.org. Disponível online (https://sdgtracker.org/peace-justice\#16.4.1) (Consultado em: 20.04.2019).

Rodrigues, G. R. F. (2019). “As Cidades como Novos Lócus dos Conflitos Contemporâneos: Uma análise da violência urbana na América Latina”. Em Muñoz, E.E., Coelho, A. L., Villamar, M. del V. (Org.), Sulatinidades: Debates do GRISUL sobre América Latina. Rio de Janeiro: Périplos.

Schiano, A., Chelbly, J., Ruiz, F. (2017). "Sustainable Development as a Path to Peacebuilding: Finding Common Ground to Counter the Extremist Narrative", Seton Hall Journal of Diplomacy and International Relations, Vol. 18, N. 1.

Sen, A. (2010). Desenvolvimento como liberdade. São Paulo: Companhia das Letras.

UNODC (United Nations Office on Drugs and Crime) (2019). Global Study on Homicide: homicide, development, and the Sustainable Development Goals. Booklet 4. Disponível online (https://www.unodc.org/unodc/en/data-and-analysis/global-study-onhomicide.html). Acesso em 16 de outubro de 2019.

UNODC (2019). Global Study on Homicide: understanding homicide - typologies, demographic factors, mechanisms and contributors. Booklet 3, Disponível online: https://www.unodc.org/unodc/en/data-and-analysis/global-study-on-homicide.html. (Consultado em: 16.10.2019).

Viggiano, J. (2018). “Cooperação regional em segurança pública: Avaliação do quadro normativo no contexto da UNASUL", Brazilian Journal of Strategy and International Relations, N. 7. 66-91. 10.22456/2238-6912.87986.

Vorrath, J., Beisheim, M. (2015). "Organised crime in the 2030 Agenda for Sustainable Development": indicators and measurements for international and national implementation", SWP Comment, Vol. 45.

Whaites, A. (2016). "Achieving the Impossible: Can We Be SDG 16 Believers?", GovNet Background Papers N. 2. Paris: OECD.

Wiberg, H. (2005). "Investigação para a Paz: Passado, presente e futuro", Revista Crítica de Ciências Sociais, N. 71, 21 -42.

Williams, P. (2008). "Violent non-state actors and national and international security", International Relations and Security Network, Vol. 25.

Estudios de la Paz y el Conflicto, Revista Latinoamericana, IUDPAS-UNAH, Volumen 1, Número 1, enero-junio 2020, pp. 74-96. DOI: 10.5377/rlpc.v1i1.9517 


\section{Acronyms}

ODS Objetivos do Desenvolvimento Sustentável.

OEA Organização dos Estados Americanos.

DCOT Departamento contra o Crime Organizado Transnacional.

UNCTOC Convenção das Nações Unidas contra o Crime Organizado Transnacional.

\section{REFERENCIA DE LOS AUTORES}

Marcos Alan S. V. Ferreira: Doutor em Ciência Política pela Unicamp (2010) e Mestre em Relações Internacionais - Programa Santiago Dantas (UNESP/UNICAMP/PUC-SP) (2006). Pesquisador/Professor Visitante na Univ. de Manchester (Reino Unido - 2018 e 2019), Univ. de Uppsala (Suecia - 2014), Univ. de Vechta (Alemanha - 2017 e 2019) e Univ. Núr (Bolívia - 2018). Atua voluntariamente em entidades educacionais da Comunidade Bahá'í como Institute for Studies in Global Prosperity e Lazos Learning. Artigos e resenhas publicados em periódicos internacionais e nacionais, tais como International Studies Perspectives, Trends in Organized Crime, Cambridge Review of International Affairs e Journal of Political Science Education. marcosalan@gmail.com. ORCID: 0000-0002-3196-6508.

Anna Beatriz Ramalho Gonçalves: Investigadora de iniciação científica, concluinte de Relações Internacionais da Universidade Federal da Paraíba. Desde 2018 é bolsista CNPq - Universidade Federal da Paraíba de iniciação científica com pesquisas sobre atores nãoestatais violentos, governança informal, crime organizado internacional e, especialmente, sobre a atuação do Primeiro Comando da Capital. Voluntária, durante o ano de 2018, do projeto de extensão social "Panorama Internacional". biaramalho2109@gmail.com. ORCID: 0000-0002-6711-4227.

Mirelle Lages Lucena: Investigadora de Iniciação Científica, concluinte do curso de Relações Internacionais da Universidade Federal da Paraíba. Em 2017 fez parte da Empresa Junior, Lideri, no cargo de Analista de Projetos, e integrou o projeto de extensão social, PROTOS. Como bolsista CNPq - Universidade Federal da Paraíba de iniciação científica, atua com pesquisas sobre as políticas públicas desenvolvidas pela OEA com base na implementação do ODS 16.4, analisando as nuances do Crime Organizado na América Latina, com base nos Estudos de Paz. mirellelucena@gmail.com. ORCID: 00000003-1023-1657

Recibido: 10-11-2019

Aceptado: 02-12-2019

(c) (i) Licencia Creative Commons Reconocimiento 4.0 (CC BY 4.0).

Estudios de la Paz y el Conflicto, Revista Latinoamericana, IUDPAS-UNAH, Volumen 1, Número 1, enero-junio 2020, pp. 74-96. DOI: 10.5377/rlpc.v1i1.9517 